Trakya Eğitim Dergisi

Cilt 9, Sayı 1

Ocak 2019, 78-90

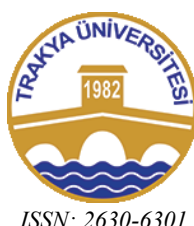

Doi: $10.24315 /$ tred.450423

Araştırma Makalesi
Trakya Journal of Education

Volume 9, Issue 1

January 2019, 78-90

\title{
Durumluk Sınav Kaygısı Ölçeği (DuSKÖ): Geçerlik ve Güvenirlik Çalışması ${ }^{1}$
}

\author{
State Test Anxiety Scale (STAS): Validity and Reliability Study \\ Alper ŞAHIN ${ }^{2}$
}

\begin{abstract}
Öz: Bu çalışmada sınav kaygısının bio-psikososyal modeline uygun bir durumluk sınav kaygısı ölçeğinin geliştirilmesi amaçlanmıştır. $\mathrm{Bu}$ amaçla oluşturulan 29 maddelik durumluk sınav kaygısı ölçeği uzman görüşleri ve öğrencilerle yapılan odak grup çalışması sonrasında 280 (120 Kadın, 140 Erkek) öğrenciye uygulanmıştır. Elde edilen verilere açımlayıcı faktör analizi (AFA) uygulanmıştır. AFA sonrası 7 madde ölçekten çıkarılmış ve bilişsel, psikososyal ve fizyolojik olmak üzere 3 alt boyuttan oluşan 22 maddelik nihai forma ulaşılmıştır. $\mathrm{Bu} 22$ madde 312 (129 Kadın, 183 Erkek) öğrenciye uygulanmış ve elde edilen veriye doğrulayıcı faktör analizi uygulanmıştır. İncelenen uyum iyiliği indekslerinin birçoğu $(\chi 2 / \mathrm{sd}=1.72, \quad \mathrm{CFI}=.96, \quad \mathrm{NNFI}=.96, \quad \mathrm{IFI}=.96, \quad \mathrm{RMSEA}=.05$, $\mathrm{SRMR}=.05)$ mükemmel seviyede uyum iyiliği değerlerini işaret etmiştir. Ölçeğin alfa iç tutarlık katsayıları Bilişsel alt boyutu için .93, Psikososyal alt boyutu için .84, Fizyolojik alt boyutu için .85 ve tüm ölçek için .94 olarak elde edilmiştir. Sonuç olarak bu çalışmada geliştirilen durumluk sınav kaygısı ölçeğinin geçerli ve güvenilir bir ölçek olduğu belirlenmiştir.
\end{abstract}

Anahtar sözcükler: Durumluk Sinav kaygısı, bio-psikososyal
model, sinav kaygısl, geçerlik, güvenirlik

Anahtar sözcükler: Durumluk Sinav kaygısı, bio-psikososyal
model, sınav kaygısl, geçerlik, güvenirlik

Cite this article as:

Şahin, A. (2019). Durumluk sınav kaygısı ölçeği (DuSKÖ): Geçerlik ve güvenirlik çalışması. Trakya Eğitim Dergisi, 9(1), 78-90.

\begin{abstract}
The aim of this study was to develop a state test anxiety scale in accordance with the bio-psychosocial model of test anxiety. For this purpose, 29 items were developed and administered to 280 (120 Female, 140 Male) students after a focus group study and expert reviews. Seven items were removed following the exploratory factor analysis in which 22 items in three factors (cognitive, psychosocial and physiological) were extracted. The final version of the scale with 22 items was administered to 312 (129 Female, 183 Male) students and its data was analyzed through confirmatory factor analysis. Most of the fit indices examined $(\chi 2 / \mathrm{sd}=1.72, \mathrm{CFI}=.96, \mathrm{NNFI}=.96, \mathrm{IFI}=.96$, $\mathrm{RMSEA}=.05, \mathrm{SRMR}=.05$ ) indicated a perfect fit of the data to the model. Alpha internal consistency coefficient of the scale was .93 for cognitive, .84 for psychosocial, .85 for physiological scales and .94 for the whole scale. As a result, it was found that the State test anxiety scale was a valid and reliable measure of state test anxiety.
\end{abstract}

Keywords: State test anxiety, bio-psychosocial model, test anxiety, validity, reliability

\section{EXTENDED ABSTRACT}

\section{Introduction}

In Turkey, individuals at all ages take tests for different purposes in all parts of their life. The majority of these tests have high influence on the future of individuals. This may cause these individuals to see tests as a means of existence. Moreover, they may also experience pressure from family and their environment. As a result, they may be forced to fight against some problems before and during the test. Test anxiety is one of these problems. In the literature, the majority of the scales used to identify test anxious students are the ones developed not specifically for test anxiety. Moreover, these scales are mostly the ones which were developed long ago. For example, State-Trait Anxiety Inventory, one of the most frequently used state anxiety scales, was developed by Spielberger, Gorsuch, and Lushene in 1970. In addition, there is, currently, no state test anxiety scale which was originally developed in Turkish. Furthermore, there are few scales which cover the bio-psychosocial model of test anxiety. Thus, the purpose of this study is to develop an up-to-date Turkish state test anxiety scale which covers the bio-psychosocial model of test anxiety as an alternative to the current test anxiety scales due to the aforementioned reasons.

\footnotetext{
${ }^{1}$ Bu çalışma Orta Doğu Teknik Üniversitesi Kuzey Kıbrıs Kampüsü Rektörlüğü Araştırma Koordinasyon Ofisi tarafından desteklenen SOSY-17-YG-3 numaralı bilimsel araştırma projesi kapsamında gerçekleştirilmiştir. Bu çalışmanın ilk bulguları 18-22 Nisan 2018 tarihleri arasında Antalya'da yapılan 28. Eğitim Bilimleri (ICES-UEBK 2018) Kongresinde sunulmuştur.

${ }^{2}$ Dr., Orta Doğu Teknik Üniversitesi, Kuzey Kıbrıs Kampusu, email : alpersahin2@yahoo.com
} 


\section{Method}

The development process of the State Test Anxiety Scale (STAS) has started with the researcher's review of the test anxiety/anxiety scales in the literature and with some unstructured interviews with a group of students who claim to experience test anxiety. After the review of the current literature and unstructured interviews, the initial form of the scale with 29 items was obtained. After this stage, the items in the initial form of the scale was reviewed by a group of experts and was revised based on their feedback. The items in the scale was piloted with a group of students in the format of a focal group for their feedback for clarity and understandability of the statements. Then, the revisions were made accordingly and the scale was administered to 280 preparatory school students of a university located in the Turkish Republic of Northern Cyprus before their third midterm exam. Benson and Elzahhar's (1994) revised test anxiety scale (RTAS) previously translated into Turkish by Akın, Demirci and Arslan (2012) was administered to the same group of students around a week before the midterm in classroom environment to compare its performance with that of STAS'. Before the administration of RTAS, consent forms were signed by the voluntary participants.

After the data was obtained from the first administration of the initial form with 29 items, in order to extract the factor structure of the scale, exploratory factor analysis with oblimin rotation was done. The KMO and Barlett tests were used to determine the feasibility of using the data for factor analysis and sufficiency of sample size. The KMO value was found to be .962 which was taken as an indicator for the sufficiency of the sample size. The result of the Barlett test $\left(X^{2}=3720.821, \mathrm{sd}=231, \mathrm{P}<.001\right)$ also indicated that the data is suitable to be used for factor analysis. Factor analysis extracted a three factor structure with 22 items. Seven items were removed from the scale due to some reasons such as having factor loadings below .40 and having high factor loadings for more than two factors and having less than three items in one factor. There were nine items related to the cognitive domain of test anxiety, so they were called as "Cognitive", five items were found to be related to the bio-psychosocial domain, so they were called as "Psychosocial" and lastly, eight items were identified as items related to physiological domain of test anxiety, so they were called as "Physiological" factors.

The final form of the scale with 22 items was administered to 312 individuals from the same population before another midterm exam. Confirmatory factor analysis was performed using the data obtained. Confirmatory factor analysis confirmed the three-factor structure of the scale with fit values indicating perfect fit $(\mathrm{CFI}=.96, \mathrm{NNFI}=.96, \mathrm{IFI}=.96, \mathrm{RMSEA}=.05, \mathrm{SRMR}=.05)$. Moreover, Cronbach's Alpha, Spearman-Brown two-halves and test-retest techniques were used to test the reliability of the scale. They all indicated that STAS is a reliable scale to measure state test anxiety of the students. Last but not least, the correlation between RTAS and STAS scale scores was found to be .73 .

\section{Results and Discussion}

The purpose of the study was to develop a Turkish state test anxiety scale covering biopsychosocial domain of test anxiety. For this purpose, STAS with 22 items was developed. Statistical analyses done with the data obtained in this study indicated that STAS was a valid and reliable means to measure state test anxiety. By the help of this scale, state test anxiety will be able to be measured for each exam taken by the students individually which was not possible with the current test anxiety scales in the field. The current test anxiety scales mostly catered for the trait level anxiety which was thought to be highly correlated with test anxiety. However, it is theorized by the author of this article that some individuals with high trait level anxiety may not develop symptoms of anxiety in all exams without any exception. Moreover, individuals who do not show symptoms of trait level anxiety may not demonstrate symptoms of test anxiety for some exams, but may at the same time experience test anxiety to an extent for some certain exams. The development of STAS will make it possible to identify such factors affecting such students negatively and making them more anxious before some tests and less anxious before some others. Furthermore, the performance of the trait level test anxiety scales and STAS can be easily compared as trait level anxiety scales are administered out of the test environment and STAS can be administered in the test environment right before each test. Last but not least, STAS is developed in accordance with bio-psychosocial model of exam anxiety. Thus, it has items covering the environmental factors negatively affecting the individuals and leveraging their exam anxiety. All in all, STAS is thought to have a voluminous contribution to the related literature with its comprehensive structure covering the most current models of test anxiety. 


\section{GİRIŞ̧}

Ülkemizde her yaştan birey hayatının neredeyse her aşamasında seçme, yerleştirme, düzey belirleme gibi nedenlerden dolayı sınavlara girmektedir. Bu sınavların birçoğu bireylerin geleceğinin şekillenmesinde önemli bir yere sahiptir. Bu nedenle bireyler sınavları bir varoluş mücadelesi gibi görebilmekte, çevresindekilerin ve ailelerinin beklentilerini bir baskı unsuru olarak hissedebilmekte ve sonuç olarak sınav öncesinde ve sırasında sınav harici bazı sıkıntılarla baş etmek durumunda kalabilmektedir. Sınav kaygısı bu sıkıntılardan bir tanesidir. Sinav kaygısının bireylerin \%25 ila $\% 40$ '1nı belirli düzeyde etkilediği tahmin edilmektedir (McDonald, 2001). Ancak bu oran ülkemizde oldukça yüksek görünmektedir. Şöyle ki, sınav kaygısı ile ilgili çalışmasında Gençdoğan (2006), çalışmasına katılan lise öğrencilerinin \%66'sının yüksek düzeyde sınav kaygısı yaşadığını tespit etmiştir. Benzer bir diğer araştırmada, Gündoğdu (1994) öğrencilerin \%69'unun yüksek sınav kaygısına sahip olduğunu belirlemiştir. Ülkemizde çok sayıda öğrencinin sınav kaygılarının yüksek olması sınav kaygısının ülkemizde bireylerin yaşadığı önemli sorunlardan biri olduğunu düşündürmekte; sınav kaygısının nedenlerinin ve sonuçlarının derinlemesine irdelenerek iyileştirici çözüm yollarının geliştirilmesinin önemine işaret etmektedir.

Bir sınava giren bazı bireylerin sınav kaygı düzeyinin orta, bazılarının ise yüksek olması ve bunun tespit edilmesine rağmen sınav başarısının her bireyi ne düzeyde etkilediğinin bilinmemesi sınav sonuçlarına bir nevi tesadüfi hata karışmasına neden olmakta ve sınav sonuçlarının güvenirliğini düşürmektedir. Çünkü bir sınavın sonuçlarının güvenirliği sınavın tesadüfi hatadan arınıklı̆̆ oranında yüksektir. Çalışmalar göstermektedir ki yüksek sınav kaygısı ile başarı arasında negatif bir ilişki vardır (Zeidner, 1998). Bir başka deyişle sınav kaygısı yükseldikçe başarı düşmektedir. Bu nedenle bireylerin her sınavdan önceki kaygı düzeylerinin tespit edilmesi ve kaygıyı azaltıcı önlemlerin alınması bu öğrencilerin sınavlardaki başarıları ve her bireyin eşit şartlarda sınava girmesi açısından önem arz etmektedir.

Spielberger (1972) kaygının durumluk (state) kaygı ve sürekli (trait) kaygı olarak iki alt boyuta sahip olduğunu belirtmektedir. Sürekli kaygı sağlıklı bireylerde görülmemektedir ve bir tür duygudurum bozukluğu belirtisidir. Durumluk kayg1 ise sadece belirli durumlarda ortaya çıkan ve herkeste görülebilen kaygı türüdür. Sınav kaygısı sınav esnasında bireyde meydana gelen istem dışı ve rahatsız edici bilişsel ve duyuşsal tepkiler olarak tanımlanabilir. Sınav kaygısının çocukluk dönemlerinde başladığı ve girilen sinavlarda başarısızlıklar arttıkça artabileceği düşünülmektedir (Karataş, Alıcı, Aydın, 2013). Ayrıca gerekli tedaviler uygulanmaması halinde çocukluktan yetişkinliğe aktarıldığı gözlemlenmiştir (Delvecchio, Cavallina, Di Riso ve Mazzeschi, 2017). Sınav kaygısının endişe (worry) ve duygusallık (emotionality) olmak üzere alanyazında kabul görmüş iki ana boyutu vardır (Liebert ve Morris, 1967). Endişe boyutu daha çok kendini değersiz hissetme, zihin dağınıklığ1, kendini akranlarıyla karşılaştırma vb. bilişsel tepkilerden oluşmaktadır (Bozkurt, Ekitli, Thomas, ve Cassady, 2017). Duyarlık ise kalp atışlarında hızlanma, mide bulantısı, artan gerginlik gibi bedensel tepkileri içermektedir (Öner, 1990). Akademik performans sınav kaygısının bilişsel boyutundan daha olumsuz etkilenmektedir (Zeidner, 1998). Hembree'ye göre bunun nedeni sınav kaygısı yüksek bireylerin sınav esnasında başarısız olacağını düşünerek ve kendini değersiz hissettirici iç konuşmalarla bilişsel olarak kendini sekteye uğratmasıdır (Aktaran: Eum ve Rice, 2011). Bu iki boyuttan başka, sınav kaygısının bio-psikososyal modeli sınav kaygısının bio-psikososyal boyutunun da bulunduğunu iddia etmektedir (Friedman ve Bendas-Jacob, 1997). Bu boyut sınav kaygısının sosyal çevreden gelecek muhtemel olumsuz tepkilerden kaynaklanan ve bireyin kaygısını artıran düşünceleri içermektedir.

Sınav kaygısı kaygının özel bir halidir ve sınav kaygısı yüksek bireylerin sürekli kaygısının da yüksek olacağı düşünülmektedir (Spielberger ve Vagg, 1995). Bu nedenle alanyazında sınav kaygısı ile ilgili ölçeklerin çoğunluğunun bireylerin sınav kaygılarını genel olarak değerlendirdikleri sürekli kaygıya yönelik ölçekler şeklinde hazırlandığı gözlemlenmiştir. Bunlardan Sınav Kaygısı Envanteri Spielberger (1980) tarafından geliştirilmiş ve Öner (1990) tarafindan Türkçe'ye uyarlanmıştır. Bu envanterde 20 madde bulunmaktadır. Ayrıca Spielberger, Gorsuch ve Lushene'e (1970) ait daha önce bahsedilen ve Türkiye'de yaygın olarak kullanılan durumluk-sürekli kaygı envanteri vardır. Bu envanter durumluk ve sürekli kaygı düzeylerini ölçen 2 ayrı ölçekte toplam 40 maddeden oluşmaktadır. Sınav kaygısını ölçmeye yönelik geliştirilen bir diğer sınav kaygısı ölçeği Driscoll’ün (2007) geliştirip ve Totan ve Yavuz'un (2009) Türkçeye uyarladığı Westside sınav kaygısı ölçeğidir. Westside sınav kaygısı ölçeği 10 maddeden oluşmaktadır. Sınav kaygısını ölçmeye yönelik bir diğer ölçek Benson ve El-Zahhar (1994) tarafından geliştirilen ve Akın, Demirci ve Arslan (2012) tarafından Türkçeye uyarlanan revize edilmiş sınav kaygısı ölçeğidir (RSKÖ). 20 maddeden oluşan bu ölçek bedensel 
belirtiler, gerginlik, sınavla ilgisiz düşünceler ve endişe alt boyutlarına sahiptir. Sınav kaygısını ölçmeye yönelik bir diğer ölçek Cassady ve Finch (2015) tarafından revize edilen ve Bozkurt, Ekitli, Thomas ve Cassady (2017) tarafindan Türkçeye uyarlama çalışması yapılan revize edilmiş bilişsel sınav kaygısı ölçeğidir. $\mathrm{Bu}$ ölçek sınav kaygısını sadece bilişsel boyutuyla ele alan 25 maddeden oluşmaktadır. Bunların yanısıra Başol (2017) tarafından Türkçe olarak geliştirilen IDA sınav kaygısı ölçeği bulunmaktadır. IDA sınav kaygısı ölçeği bilişsel ve Fizyolojik tepkileri içeren 9 madde ve sosyal çevre ile ilgili düşünceleri içeren 6 madde ile toplamda 15 maddeden oluşan bir sınav kaygııı ölçeğidir.

Durumluk kaygıya yönelik hazırlanmış ulaşılabilen tek ölçek Spielberger, Gorsuch ve Lushene (1970) tarafından hazırlanmış durumluk-sürekli kaygı envanteridir (State-Trait Anxiety Inventory). Milli eğitim bakanlığına bağlı okullarda rehberlik servisleri tarafindan yaygın olarak kullanılan bu envanter bir tanesi durumluk kaygıya yönelik 20 madde, diğeri sürekli kaygıya yönelik 20 madde olmak üzere toplam 40 maddeden oluşan iki ölçekten ibarettir. Ancak bu envanter sınav kaygısına özel olarak hazırlanmamıştır ve oldukça eskidir. Envanterde bulunan durumluk kaygı ölçeği incelendiğinde içerdiği 20 maddenin önemli bir kısmının birbirini tekrarlayan ve özellikle katılımcılar tarafından birbirinden ayırt edilmesi çok zor maddeleri (Örn. "şu an keyfim yerinde", "kendimi rahatlamış hissediyorum", "şu an huzur içindeyim", "kendimi rahat hissediyorum" vb.) içerdiği belirlenmiştir. Bahsi geçen bu maddeler ters puanlanan maddelerdir. Ölçekte bunlarla birlikte ters puanlanan toplam 10 madde vardır. Normal puanlanan maddelerde de benzer bir sorun söz konusudur. Örneğin "Şu an asabım bozuk", "Şu an çok sinirliyim", "Şu an sinirlerim gergin" gibi aynı anlama gelebilecek ve birbirinden ayırt etmesi zor 3 ifade 3 ayrı maddeyi oluşturmaktadır. Bu durumun durumluk sınav kaygısını ölçmekte yaygın olarak kullanılan bu ölçeğe yanıt veren bireylerin bu ve benzer maddeleri birbirinden ayırt edemeyerek aynı veya çok yakın yanıtlar vermesine neden olarak kaygı düzeyi düşük bireylerin orta, orta düzeydeki bireylerin ise yüksek kaygı düzeyinde tanılanarak kayg1 düzeylerinin olduğundan daha yüksek algılanmasına neden olabileceğini düşündürmektedir. Ayrıca ölçekte dikkat çeken bir başka önemli nokta ise aynı ölçekte bazı ters puanlanan maddeler ile normal puanlanan maddelerin birebir karşıt ifadeler içermesidir. Örneğin "Şu anda hiç keyfim yok" ve "Şu anda keyfim yerinde" birbirine zit ifadelerdir ve birisine "tamamıyla" yanıtını veren bireyin diğerine de "Hiç" yanıtını vermesi beklenir. $\mathrm{Bu}$ durum da yine daha önce bahsedilen çok benzer maddelerin yol açtığı düşük kaygı düzeyindekilerin orta, orta kaygı düzeyindekilerin ise yüksek ve çok yüksek olarak tanılanmasına katkı sağlayabilecek potansiyele sahiptir.

Sonuç olarak öğrencilerin her bir sınav için ayrı tepki verecekleri ve her bir sınav öncesi ayrı ayrı yanıtlayabilecekleri güncel bir durumluk sınav kaygısı ölçeğinin sınav kaygısı hakkında daha geçerli ve güvenilir sonuçlar elde edilmesini sağlayacağı düşünülmektedir. Çünkü sürekli kaygısı düşük bireylerin bazı sınavlardan önce kaygı düzeylerinin normalden fazla yükselebileceği, sürekli kaygısı yüksek bireylerin ise her farklı sınavda aynı düzeyde yükselmeyeceği düşünülmektedir. Öğrencilerin özellikle hangi sınavlardan önce kaygı düzeylerinin arttığı ya da azaldığının belirlenebilmesi için öğrencilerin sınav öncesi o anki kaygı düzeylerini ölçecek geçerli ve güvenilir güncel bir durumluk sınav kaygısı ölçeğine ihtiyaç bulunmaktadır. Ayrıca alanyazında sınav kaygısının bio-psikososyal boyutunu da içeren sınav kaygısı ölçekleri oldukça sınırlı sayıdadır. Bu nedenle bu çalışmanın amacı alanyazında eksikliği hissedilen hem durumluk sınav kaygısına yönelik hem de sınav kaygısının biopsikososyal boyutunu da içeren kapsamlı Türkçe bir durumluk sınav kaygısı ölçeğinin geliştirilerek sınav kaygısı üzerine araştırma yapan araştırmacıların kullanımına sunmaktır.

\section{YÖNTEM}

Ölçek maddelerinin oluşturulması için Kuzey Kıbrıs Türk Cumhuriyeti’nde konuşlu özel bir üniversitede öğrenim gören ve sınav kaygısı yaşadığını ifade eden bir grup öğrenci ile yapılandırılmamış görüşmeler yapılmıştır. Ayrıca literatürde sınav kaygısı üzerine yapılmış çalışmalar ve oluşturulan ölçekler incelenmiştir (Akın, Demirci, ve Arslan, 2012; Başol, 2017; Benson ve ElZahhar, 1994; Bozkurt, Ekitli, Thomas, ve Cassady, 2017; Cassady ve Finch, 2015; Driscoll, 2007; Friedman ve Bendas-Jacob, 1997; Lowe ve diğerleri, 2007; Öner, 1990; Spielberger, 1972; Spielberger, Gorsuch ve Lushene, 1970; Spielberger ve Vagg, 1995). Literatür taramas1, görüşmeler ve mevcut ölçeklerin incelenmesi sonucu alanyazında da geçtiği üzere kendini değersiz hissetme, zihin dağınıklığı, kendini akranlarıyla karşılaştırma gibi bilişsel boyutta; hızlı kalp atışı, baş ağrısı, gerginlik gibi bedensel tepkileri içeren fizyolojik boyutta ve mevcut ölçeklerin çoğunda bulunmayan ve son yıllarda popülerlik kazanan bio-psikososyal boyutta (Friedman ve Bendas-Jacob, 1997; Lowe ve diğerleri, 2007) "1-Hiç", "2-Biraz", "3-Orta düzeyde", "4-Çok" şeklinde tepkiler içeren toplam 29 maddeden oluşan ilk forma 
ulaşılmıştır. Ölçeğin 29 maddelik bu ilk formu ölçme değerlendirme, Türkçe ve PDR uzmanlarından oluşan bir uzman grubunun görüşüne sunulmuştur. Uzman grubundan alınan dönütlerle ölçek maddelerinde istenen değişiklikler yapılmıştır. Sonraki aşamada bir grup öğrenciyle bir odak grubu çalışması yapılmış ve öğrencilerden maddelerin açık ve anlaşılırlığ üzerine dönüt alınarak ölçeğin 29 maddelik deneme formu elde edilmiştir.

Ölçeğin deneme formunun uygulanması öncesinde ilgili üniversitenin etik kurulundan ve yabanc1 diller okulu akademik kurulundan gerekli izinler alınmıştır. Ayrıca öğrencilerin tümü ile sınıf ortamında yüz yüze görüşülmüş ve gönüllü katılımcı formları imzalatılarak Benson ve El-zahhar (1994) tarafından geliştirilen ve Akın, Demirci ve Arslan (2012) tarafından Türkçe'ye uyarlanan RSKÖ uygulanmıştır. $\mathrm{Bu}$ birçok farklı kültürde güvenirlik ve geçerlik çalışmaları yapılmış bir ölçektir. Bu ölçeğin seçilmesinde bir diğer etken dört alt boyutundan ikisi olan gerginlik ve bedensel belirtiler boyutlarının geliştirilmek istenen durumluk sınav kaygısı ölçeğinin bilişsel ve fizyolojik alt boyutları ile örtüşmesidir. Bu ölçeğin uygulamasına 160 erkek 120 kız olmak üzere mühendislik ve sosyal bilimler alanlarından 8 farklı bölümden gönüllü katılımcı formu imzalayan toplam 280 hazırlık sınıfı öğrencisi katılmıştır. Geliştirilen durumluk sınav kaygısı ölçeğinin deneme uygulaması ölçeğin durumluk sınav kaygısı ölçeği olmasından dolayı hazırlık sınıflarının 3. ara sınavından 5 dakika önce yapılmıştır. Deneme uygulamasına daha önce gönüllü katılımcı formu imzalayan 280 öğrenci (Tablo 1) katılmıştır. 280 öğrencinin 143'ü sosyal bilimler 137'si ise fen bilimleri öğrencileridir.

Deneme uygulamasından elde edilen verilere SPSS 24 (IBM Corp, 2016) kullanılarak açımlayıcı faktör analizi (AFA) tekniklerinden temel bileşenler analizi uygulanmıştır. Bu uygulamada eğik döndürme tekniklerinden oblimin döndürme tekniği kullanılmıştır.

Verilerin Faktör analizine uygunluğunun incelenmesi için Kaiser-Mayer-Olkin değerine, çok değişkenli normallik varsayımının test edilmesi için ise Bartlett Küresellik testi değerine bakılmıştır. Bir maddenin ilgili alt boyutta yük aldığının kabul edilmesi için en az .40 faktör yüküne sahip olması şartı benimsenmiştir. Aynı zamanda iki boyutta faktör yüküne sahip maddeler arasında en az .10 fark olması şartı gözetilmiş ve daha az fark olan maddeler ölçekten çıkarılmıştır.Ayrıca tek boyutta 3'den az madde bulunması durumunda bu maddeler de testten çıkarılmıştır. Ölçekten madde çıkarma işlemi sıra ile yapılmıştır.

Ölçeğin açımlayıcı faktör analizi ile elde edilen faktör yapısının doğrulanması ve yapı geçerliğine yönelik bulguların sağlamlaştırılması amaciyla nihai uygulaması aynı evrenden 129'u kadın 183'ü erkek olmak üzere toplam 312 öğrenciye 5. ara sınav öncesi tekrar uygulanmıştır. Elde edilen veriye Lisrel 8.50 (Jöreskog ve Sörbom, 2001) ortamında doğrulayıcı faktör analizi uygulanmıştır.

Tablo 1. Deneme uygulaması katılımcılarının bölümlerine göre frekans dağılımı

\begin{tabular}{lcr}
\hline & Frekans & $\%$ \\
\hline Hava.ve uzay Müh. & 18 & 6.4 \\
İsletme & 23 & 8.2 \\
Kimya Müh. & 4 & 1.4 \\
Bilg. Müh. & 22 & 7.9 \\
İns. Müh. & 23 & 8.2 \\
Ekonomi & 8 & 2.9 \\
Elek. Elekt. Müh. & 34 & 12.1 \\
İng. Öğrt. & 10 & 3.6 \\
Rehb. ve Psi. Dan. & 26 & 9.3 \\
Makina Müh. & 26 & 9.3 \\
Pet. ve Doğalgaz Müh. & 10 & 3.6 \\
Politik Bilimler ve Ulus. İliş. & 21 & 7.5 \\
Psikoloji & 55 & 19.6 \\
\hline Total & 280 & 100.0 \\
\hline
\end{tabular}

Ölçeğin dış ölçüt geçerliğinin tespiti için daha önce uygulanan RSKÖ ve geliştirilen ölçekten elde edilen toplam puan ve alt boyutları arasındaki Pearson momentler çarpımı korelasyon değerlerine bakılmıştır. Ölçeğin güvenirliğinin tespiti için Cronbach alfa, Spearman-Brown iki yarı güvenirliği ve test-tekrar test yöntemlerine başvurulmuştur. Test-tekrar test güvenirlik katsayısının hesaplanması için aynı evrenden ölçeğin nihai uygulamasına katılmış 42 Kadın 65 Erkek toplam 108 (1 kişi her iki uygulamada da cinsiyetini belirtmemiştir) öğrenciden 6. ara sınav öncesi veri toplanarak bu ögrencilerden 5. ara sınav öncesi elde edilen toplam puanları arasındaki Pearson momentler çarpımı korelasyon değerleri incelenmiştir. Son olarak ölçek maddelerinin ayırt ediciliğinin tespiti için deneme 
uygulamasında elde edilen ölçek toplam ve alt puanları üzerinden \%27'lik alt ve üst grupların puanlarına bağımsız gruplar t-testi uygulanmıştır.

\section{BULGULAR}

Bu çalışmada, kaygının psikososyal boyutunu da içeren güvenilir ve geçerli bir durumluk sınav kaygısı ölçeğinin geliştirilmesi amaçlanmıştır. $\mathrm{Bu}$ amaçla oluşturulan ölçekle veri toplanmış ve toplanan veri yöntem bölümünde bahsi geçen bir dizi işlemden geçirilmiştir. Bu kısımda bu işlemlerden elde edilen bulgulardan bahsedilecektir.

Öncelikle AFA öncesi Kaiser-Mayer-olkin testi değerine bakılmıştır. Bu değer .926 gibi oldukça yüksek bir değer almıştır. Ayrıca Bartlett Küresellik testinin de manidar $\left(X^{2}=3720.821\right.$, sd=231, $\mathrm{P}<$ .001) olduğu belirlenmiştir. Bu sonuçlarla kullanılan örneklemin AFA için yeterli olduğu ve AFA için gerekli varsayımların karşılandığı tespit edilmiştir.

Tabachnick ve Fidell (2012), maddelerin faktör yükü değerlerinin en az .32 olması gerektiğini ifade etmektedirler. Ancak bu çalışmada AFA sonucunda elde edilen faktör yükü değerlerine göre .40 altında kalan, iki faktörde aralarında .10'dan daha az farkla yük değerleri alan ve tek boyutta yük değeri alan 3'ten daha az sayıda madde olması nedenleriyle toplam 7 madde sırasıyla ölçekten çıkarılmıştır. Ayrıca kalan tüm maddeler için alt-üst \%27'lik öğrenci gruplarının ölçek puanları kullanılarak ayırdedicilik seviyeleri bağımsız gruplar t-testi, madde-toplam korelasyonu ve ortak varyans değerleri incelenmiştir (Bkz. Tablo 2). Bu aşamada 10. ve 17. maddelerin ortak varyanslarının düşük olduğu tespit edilmiştir. $\mathrm{Bu}$ maddelerin madde-toplam korelasyonlarına, faktör yüklerine ve ölçekten çıkarılmaları halinde alfa değerlerine etkisine bakılmıştır. Alanyazında (Erkuş, 2012) madde-toplam korelasyonunun en az .30 olması önerilmektedir. Bu maddelerin faktör yüklerinin .40'un üzerinde, madde-toplam korelasyonlarının .30'un üzerinde olması ve silinmeleri durumunda alfa iç tutarlık katsayısının yükselmesine katkılarının yok denecek kadar az olması nedeniyle ölçekte kalmalarına karar verilmiştir.

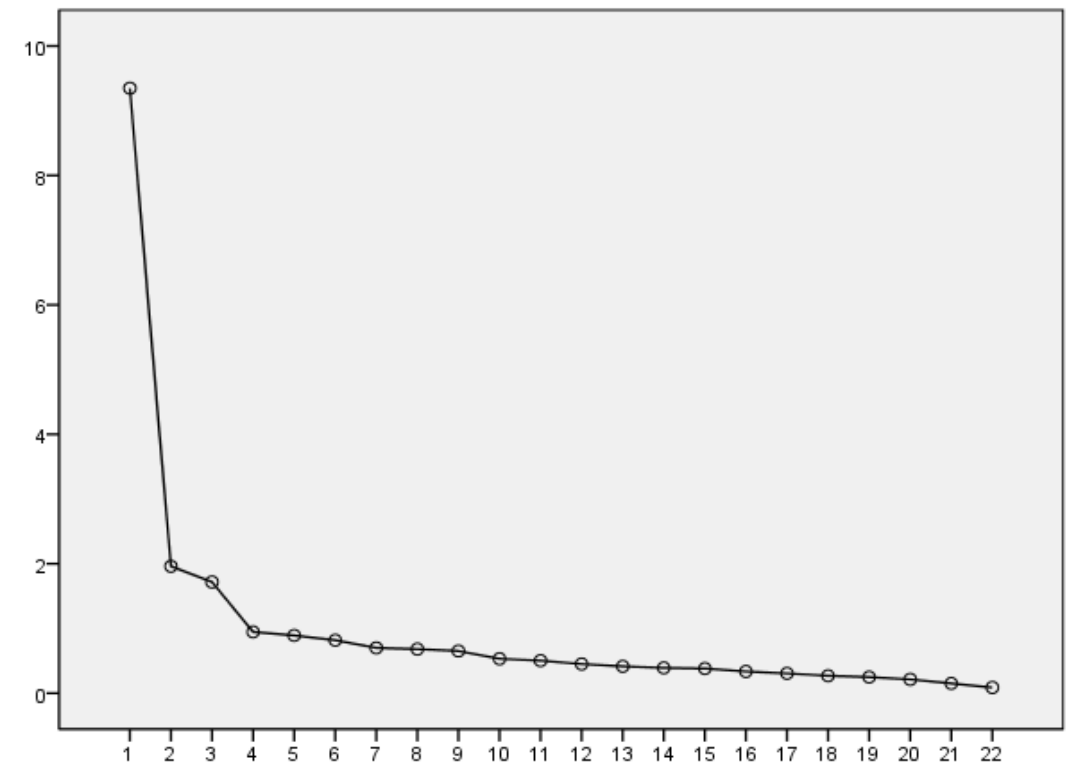

Şekil 1. Durumluk sınav kaygısı ölçeği (DuSKÖ) yamaç birikinti grafiği

AFA sonucu elde edilen yamaç birikinti grafiği (Bkz. şekil 1) incelendiğinde ilk özdeğerden sonra keskin bir düşüş olduğu ve takip eden iki özdeğerden sonraki özdeğerlerin arasında yüksek farklar olmadığı gözlenmektedir. Sonuç olarak ölçeğin başat bir faktöre sahip özdeğeri 1.00 'den büyük 3 faktörde toplanmış 22 maddelik nihai formuna ulaşılmıştır. 3 boyutun toplam varyansın \%59.21'ini açıkladığı belirlenmiştir (Bkz. tablo 2).

Birinci boyutta ölçeğin yazılması sürecinde oluşturulan kaygının Bilişsel boyutundaki maddeleri içermesinden dolayı "Bilişsel boyut" olarak adlandırılmıştır. Bu boyutta maddelerin faktör yükleri .63 ile .91 arasında değerler almıştır. Bilişsel boyutun toplam varyansın \%42.49'unu karşıladığ 1 belirlenmiştir. İkinci boyutta ölçek maddeleri yazılırken göz önünde bulundurulan bio-psikososyal boyuta yönelik maddelerin toplandığı belirlendiği için bu boyut "Psikososyal boyut" olarak adlandırılmıştır. Bu boyuttaki maddelerin faktör yükleri .65 ile .87 arasında değişmektedir. Bu boyutun 
Tablo 2. DuSKÖ deneme uygulamasına ait bulgular

\begin{tabular}{|c|c|c|c|c|c|c|c|c|c|c|}
\hline & Madde & f1 & $\mathrm{f} 2$ & f3 & $\begin{array}{c}\text { Ortak } \\
\text { Varyans }\end{array}$ & $\begin{array}{c}\text { Madde toplam } \\
\text { korelasyonu }\end{array}$ & $\begin{array}{c}\text { Madde } \\
\text { silinmesi } \\
\text { durumunda } \\
\text { Alfa değeri }\end{array}$ & $\begin{array}{l}\% 27 \text { alt üst } \\
\text { gruplar } \\
\text { ortalama fark1 }\end{array}$ & $t$ değeri & $\begin{array}{c}\text { Karşı1lanan } \\
\text { Varyans }\end{array}$ \\
\hline \multirow{9}{*}{$\begin{array}{l}\text { B } \\
\text { I } \\
\text { L } \\
\text { İ } \\
\text { S } \\
\text { S } \\
\text { E } \\
\text { L }\end{array}$} & M6 & .66 & & & .67 & .72 & .928 & 2.01 & $18.84 *$ & \multirow{9}{*}{$\% 42.49$} \\
\hline & M15 & .61 & & & .51 & .65 & .930 & 1,83 & $14.12^{*}$ & \\
\hline & M18 & .91 & & & .82 & .79 & .927 & 2.36 & $26,35^{*}$ & \\
\hline & M19 & .91 & & & .77 & .73 & .928 & 2.39 & $20.17 *$ & \\
\hline & M20 & .75 & & & .52 & .58 & .931 & 1.89 & $14.09 *$ & \\
\hline & M21 & .86 & & & .77 & .77 & .927 & 2.23 & $22.71^{*}$ & \\
\hline & M22 & .73 & & & .67 & .74 & .928 & 2.17 & $19.68^{*}$ & \\
\hline & M25 & .72 & & & .48 & .56 & .931 & 1.76 & $14.43^{*}$ & \\
\hline & M26 & .63 & & & .61 & .73 & .928 & 2.29 & $21.19^{*}$ & \\
\hline $\mathrm{P}$ & M23 & & .80 & & .73 & .61 & .930 & 1.09 & $8.06^{*}$ & \multirow{5}{*}{$\% 8.91$} \\
\hline $\begin{array}{l}\text { S } \\
\dot{I}\end{array}$ & M24 & & .78 & & .72 & .61 & .930 & 1.11 & $7.74^{*}$ & \\
\hline $\begin{array}{l}\mathrm{K} \\
\mathrm{O}\end{array}$ & M27 & & .87 & & .71 & .49 & .932 & .69 & $5.62^{*}$ & \\
\hline $\begin{array}{l}\mathrm{S} \\
\mathrm{O}\end{array}$ & M28 & & .65 & & .45 & .44 & .934 & 1.23 & $7.45^{*}$ & \\
\hline S & M29 & & .78 & & .64 & .54 & .931 & 1.15 & $7.84^{*}$ & \\
\hline $\mathrm{F}$ & M1 & & & .59 & .45 & .53 & .932 & 1.05 & $8.63^{*}$ & \multirow{8}{*}{$\% 7.81$} \\
\hline $\begin{array}{l}\mathrm{I} \\
7\end{array}$ & M2 & & & .66 & .52 & .56 & .931 & 1.19 & $10.08^{*}$ & \\
\hline $\mathrm{Y}$ & M10 & & & .50 & .31 & .43 & .933 & 1.11 & $7.47^{*}$ & \\
\hline $\mathrm{O}$ & M17 & & & .48 & .25 & .38 & .933 & .44 & $4.21 *$ & \\
\hline $\begin{array}{l}\mathrm{L} \\
\mathrm{O}\end{array}$ & M7 & & & .86 & .69 & .57 & .931 & 1.05 & $8.65^{*}$ & \\
\hline $\mathrm{J}$ & M8 & & & .82 & .62 & .53 & .932 & 0.85 & 7.11 & \\
\hline İ & M14 & & & .67 & .47 & .49 & .932 & 1.05 & 7.49 & \\
\hline K & M16 & & & .45 & .64 & .75 & .928 & 1.93 & $16.23 *$ & \\
\hline
\end{tabular}

$* \mathrm{p}<0.001$

toplam varyansın \%8.91'ini karşıladığı belirlenmiştir. Üçüncü boyut ise bedensel tepkileri içeren fizyolojik boyutta maddelerden oluştuğu için "fizyolojik boyut" olarak adlandırılmıştır. Bu boyutta toplanan maddelerin faktör yüklerinin .45 ile .86 arasında değiştiği gözlemlenmiştir. Ayrıca bu boyutun toplam varyansın \%7.81'ini karşıladığı belirlenmiştir.

\subsection{Doğrulayıcı Faktör Analizi (DFA)}

AFA sonucu tespit edilen 3 faktörlü yapının doğrulanması amacı ile aynı evrenden farklı bir grup $(n=312)$ ögrenciye 5. ara sınav öncesi ölçeğin nihai formunun tekrar uygulanmasının ardından elde edilen verilere Lisrel 8.50 (Jöreskog ve Sörbom, 2001) ortamında DFA uygulanmıştır. Önerilen istatistiksel düzeltme işlemleri sonrası Lisrel 8.50 (Jöreskog ve Sörbom, 2001) tarafından rapor edilen uyum iyiliği değerleri Tablo 3 'te gösterilmiştir.

Tablo 3 incelendiğinde, uyum iyiliği indekslerinden altısından ( $\chi 2$ /sd, CFI, NNFI, IFI, RMSEA, SRMR) mükemmel, üçünden (GFI, AGFI, NFI) kabul edilebilir düzeyde değerler elde edildiği görülmektedir. Bu değerler AFA sonucu elde edilen 3 faktörlü modelin yeniden toplanan verilerde de doğrulandığı ve verinin bu modele mükemmel uyum gösterdiğinin kanıtı olarak görülmektedir. DFA'dan elde edilen sonuçlar Şekil 2'de gösterilmiştir. 
Tablo 3. Nihai uygulama sonrası DFA Uyum iyiliği değerleri*

\begin{tabular}{ccccc}
\hline İndeks & Mükemmel Değerler* & $\begin{array}{c}\text { Kabul Edilebilir } \\
\text { Değerler* }\end{array}$ & $\begin{array}{c}\text { Çalışmada elde } \\
\text { edilen değer }\end{array}$ & Sonuç \\
\hline$\chi 2 / s d$ & $0 \leq \chi^{2} / \mathrm{sd} \leq 2$ & $2 \leq \chi^{2} / \mathrm{sd} \leq 3$ & 1.72 & Mükemmel \\
AGFI & $.90 \leq \mathrm{AGFI} \leq 1.00$ & $.85 \leq \mathrm{AGFI} \leq .90$ & .88 & Kabul edilebilir \\
GFI & $95 \leq \mathrm{GFI} \leq 1.00$ & $.90 \leq \mathrm{GFI} \leq 95$ & .91 & Kabul edilebilir \\
NNFI & $.95 \leq \mathrm{NNFI} \leq 1.00$ & $.90 \leq \mathrm{NNFI} \leq .95$ & .96 & Mükemmel \\
CFI & $.95 \leq \mathrm{CFI} \leq 1.00$ & $.90 \leq \mathrm{CFI} \leq .95$ & .96 & Mükemmel \\
IFI & $.95 \leq \mathrm{IFI} \leq 1.00$ & $.90 \leq \mathrm{IFI} \leq .95$ & .96 & Mükemmel \\
NFI & $.95 \leq \mathrm{NFI} \leq 1.00$ & $.90 \leq \mathrm{NFI} \leq .95$ & .92 & Kabul edilebilir \\
SRMR & $.00 \leq \mathrm{SRMR} \leq .05$ & $.05 \leq \mathrm{SRMR} \leq .10$ & .05 & Mükemmel \\
RMSEA & $.00 \leq \mathrm{RMSEA} \leq .05$ & $.05 \leq \mathrm{RMSEA} \leq .08$ & .05 & Mükemmel \\
\hline
\end{tabular}

*Çokluk, Şekercioğlu, ve Büyüköztürk, 2010; Kahraman, Özbaşı, ve Özdemir, 2018; Schermelleh-Engel ve Moosbrugger, 2003

\subsection{Dış ölçüt geçerliği}

Ölçeğin dış ölçüt geçerliğinin tespiti için geliştirilen DuSKÖ toplam ve alt puanları ile RSKÖ toplam ve alt boyutları arasındaki korelasyona bakılmıştır. Elde edilen korelasyon katsayıları Tablo 4 'te gösterilmiştir. DuSKÖ'nün Fizyolojik boyutu ile RSKÖ'nün Bedensel belirtiler alt boyutunun .69 gibi yüksek bir korelasyona sahip olduğu tespit edilmiştir. Aynı şekilde DuSKÖ'nün Bilişsel alt boyutu da RSKÖ'de benzer maddeleri içeren Gerginlik alt boyutu arasındaki korelasyon katsayısı .73 olarak belirlenmiştir.

Tablo 4. RSKÖ ile toplam ve alt boyutlarına göre korelasyonlar

\begin{tabular}{lccccc}
\hline & Gerginlik & $\begin{array}{c}\text { Bedensel } \\
\text { Belirtiler }\end{array}$ & Endişe & $\begin{array}{c}\text { İlgisiz } \\
\text { Düşünceler }\end{array}$ & $\begin{array}{c}\text { RSKÖ } \\
\text { Toplam }\end{array}$ \\
\hline Fizyolojik & $.61^{* *}$ & $.69^{* *}$ & $.52^{* *}$ & $.25^{* *}$ & $.66^{* *}$ \\
Psikososyal & $.43^{* *}$ & $.39^{* *}$ & $.49^{* *}$ & $.24^{* *}$ & $.50^{* *}$ \\
Bilişsel & $.73^{* *}$ & $.47^{* *}$ & $.63^{* *}$ & $.22^{* *}$ & $.67^{* *}$ \\
DuSKÖ Toplam & $.73^{* *}$ & $.60^{* *}$ & $.27^{* *}$ & $.73^{* *}$ & $.73^{* *}$ \\
\hline
\end{tabular}

** $\mathrm{p}<0.001$

DuSKÖ Psikososyal alt boyutu ile en yüksek korelasyonu RSKÖ'nün Endişe ( $r=.43)$ alt boyutu vermiştir. Ancak RSKÖ'de DuSKÖ'nün bu alt boyutunu tam olarak karşlayan bir alt boyut bulunmamaktadır. Bu durum da Psikososyal boyutun farklı bir boyut olduğu ve DuSKÖ'nün bu boyutu diğer boyutlardan ayırt etmekte başarılı olduğunun bir göstergesi olarak alınmıştır. Her iki ölçeğin toplam puanları arasındaki korelasyon ise .73 olarak bulunmuştur. Bu sonuçlar birisi sürekli kaygıyı diğeri durumluk kaygıyı temele alan bu iki ölçeğin alt boyutları ve toplam puanlarının birbiri ile tutarlı şekilde yüksek korelasyona sahip olduğu belirlenmiştir. Bu bulgular RSKÖ ve DuSKÖ'nun ortak bir yapıyı test eden farklı iki ölçek olduğunun göstergesi olarak alınmıştır. 


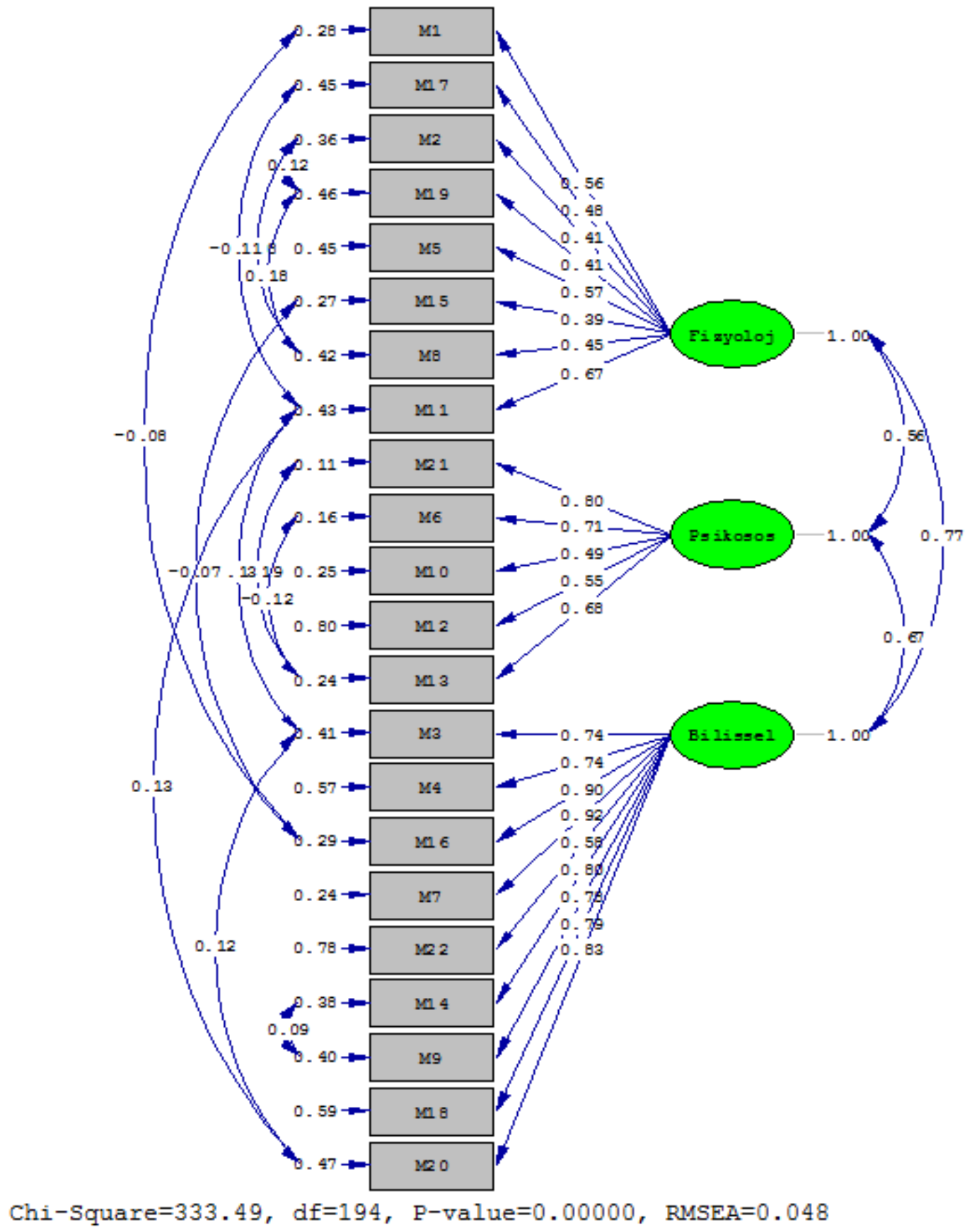

Şekil 2. DuSKÖ nihai uygulaması sonrası doğrulayıcı faktör analizine ilişkin sonuçlar

\subsection{Alt boyutlar arası korelasyon}

DuSKÖ'nün Fizyolojik, Psikososyal ve Bilişsel alt boyutlarını içeren alt ölçeklerinin birbiri ile korelasyon katsayıları Tablo 5'te gösterilmiştir. Bu tablo incelendiğinde ölçek toplam puanı ile en yüksek korelasyonu .94 ile Bilişsel boyut gösterirken, fizyolojik boyut .82 ve psikososyal boyut ise .78 gibi yüksek korelasyon katsayılarına ulaşmıştır. Fizyolojik boyut ile bilişsel boyut arasındaki korelasyon $.65 \mathrm{iken}$, psikososyal boyut ile arasındaki korelasyon .49 olarak bulunmuştur. Psikososyal boyutun Bilişsel boyut ile korelasyonunun ise .65 olduğu gözlenmiştir. Bu durum ölçeğin psikososyal boyutunun diğer boyutlar ile korelasyonunun nispeten daha düşük olduğunun göstergesi olarak alınmıştır. Alt boyutların ölçek toplam puanı ile korelasyonları yüksek bulunmuştur. Alanyazında birçok ölçekte bulunmayan psikososyal boyutun diğer alt boyutlarla nispeten düşük korelasyon değerlerine sahip olup ölçek toplamı ile yüksek korelasyona sahip olması bu boyutun diğer alt boyutlardan farklı bir boyut olduğunun ve ölçek tarafından bu farklı alt boyutun başarılı bir şekilde ayırdedildiğinin göstergesi olarak değerlendirilmiştir. 
Tablo 5. Alt boyutlar arası korelasyon

\begin{tabular}{lcccc}
\hline & Bilişsel & Psikososyal & Fizyolojik & Toplam \\
\hline Bilişssel & 1.00 & $.65^{* *}$ & $.65^{* *}$ & $.94^{* *}$ \\
Psikososyal & & 1.00 & $.49^{* *}$ & $.78^{* *}$ \\
Fizyolojik & & & 1.00 & $.82^{* *}$ \\
Toplam & & & & 1.00 \\
\hline
\end{tabular}

$* * \mathrm{p}<0.001$

\section{4. Ölçeğin Güvenirliği}

Ölçeğin güvenirliği Cronbach alfa, Spearman-Brown iki yarılar ve test-tekrar test güvenirlik katsayılarının hesaplanması ile test edilmiştir. Bulgular Tablo 6'da gösterilmiştir. Ölçeğin fizyolojik alt boyutunun .85 , psikososyal alt boyutunun .84 , bilişsel alt boyutunun ise .93 alfa güvenirlik katsayısına sahip olduğu belirlenmiştir. Ölçeğin tümünün alfa güvenirlik katsayısı ise .94 gibi oldukça yüksek bir değer almıştır. Spearman-Brown iki yarılar tekniği ile elde edilen güvenirlik katsayıları ise sırasıyla .89, $.86, .94$ ve .96 olmuştur. Bu iki yöntemin yanısıra test-tekrar test güvenirlik katsayısının hesaplanması için ölçek 5. ara sınavda uygulanmasından yaklaşık 4 hafta sonra 6 . ara sınav öncesi daha önce 5 . ara sınavda ölçeğe yanıt veren 108 öğrenciye tekrar uygulanmıştır. Bu uygulama sonucu iki uygulama sonrası elde edilen ölçek puanları arasındaki Pearson momentler çarpımı korelasyon değerleri hesaplanmıştır. Bu değerler yine sırasıyla $.74, .80, .78$ ve .81 olarak elde edilmiştir. Elde edilen tüm bu bulgular DuSKÖ’nün güvenilir bir ölçek olduğunun kanıtı olarak görülmüştür.

Tablo 6. Ölçekten elde edilen güvenirlik katsayıları

\begin{tabular}{lccc}
\hline & Cronbach Alfa & $\begin{array}{c}\text { Spearman- Brown İki yarılar } \\
\text { güvenirliği }\end{array}$ & $\begin{array}{c}\text { Test-Tekrar test güvenirliği } \\
(\mathrm{n}=108)\end{array}$ \\
\hline Fizyolojik & .85 & .89 & $.74^{* *}$ \\
Psikososyal & .84 & .86 & $.80^{* *}$ \\
Bilişsel & .93 & .94 & $.78^{* *}$ \\
Toplam & .94 & .96 & $.81^{* *}$ \\
\hline
\end{tabular}

$* * \mathrm{P}<0.001$

\subsection{DuSKÖ'den alınan puanların değerlendirilmesi}

DuSKÖ 22 maddeden oluşmaktadır. Ölçekten elde edilebilecek en düşük toplam puan 22 olurken, en yüksek toplam puan ise $88^{\prime}$ 'dir. Bilişsel alt boyutu ekte bulunan nihai uygulamada kullanılan $3,4,7,9,14,16,18,20,22$ numaralı 9 maddeyi içermektedir. Bu alt boyuttan elde edilebilecek en düşük puan 9, en yüksek puan 36'dır. Psikososyal alt boyut nihai uygulamada kullanılan 6, 10, 12, 13, 21 numaralı toplam 5 maddeden oluşmaktadır. Bu boyuttan elde edilebilecek en düşük puan 5, en yüksek puan 20'dir. Son olarak fizyolojik alt boyut nihai uygulamadaki 1, 2, 5, 8, 11, 15, 17, 19 numaralı toplam 8 maddeyi içermektedir ve bu boyuttan elde edilebilecek en düşük puan 8 , en yüksek puan 32'dir. Ölçekte ters kodlanması gereken madde bulunmamaktadır.

\section{TARTIŞMA ve SONUÇ}

Bu çalışmanın başlangıç noktası alanyazında kaygının psikososyal boyutunu da içeren ve her bir sınav öncesindeki kaygı düzeyinin anlık olarak ayrı ayrı belirlenmesine imkan verecek güvenilir ve geçerli Türkçe bir durumluk sınav kaygısı ölçeğinin bulunmamasının tespit edilmesidir. Bu tespitin ardından alanyazına bu tür bir ölçeğin kazandırılması amacıyla ölçek geliştirme çalışmalarına başlanmıştır. Ölçeğin kapsam geçerliğinin üst düzeyde olması için öncelikle ilgili alanyazın taraması yapılması, alanyazındaki diğer ölçeklerin incelenmesi ve sınav kaygısı yaşayan bir grup öğrenci ile yapılandırılmamış görüşmeler yapılması sonucu 29 maddelik deneme formu oluşturularak uzman görüşüne sunulmuştur. Uzman görüşleri doğrultusunda maddelerde gerçekleştirilen değişiklikleri müteakip ölçeğin 29 maddelik deneme formu Kuzey Kıbrıs Türk Cumhuriyeti'nde faaliyet gösteren bir özel üniversitenin hazırlık sınıfına devam eden 280 öğrenciye 3. ara sınav öncesinde uygulanmıştır. Elde edilen verilere AFA uygulanmıştır. AFA sonucu 29 maddeden 7'si ölçekten çıkarılmış ve 3 alt boyutta toplam 22 maddelik ölçeğin nihai formu elde edilmiştir. 3 alt boyuta literatürdeki benzer ölçekler baz alınarak sınav öncesi bilişsel çekinceleri içeren 9 maddeden oluşan "Bilişsel boyut", sınava 
yönelik çevresel etkenlerle ilgili düşünceleri içeren ve 5 maddeden oluşan "Psikososyal boyut" ve sinav öncesi bedensel tepkileri içeren ve 8 maddeden oluşan "Fizyolojik boyut" adı verilmiştir. AFA sonucu oluşan ölçek yapısının doğrulanması için ölçeğin 22 maddelik nihai formu aynı evrenden 312 öğrenciye 5. ara sınav öncesi tekrar uygulanmıştır. Ölçeğin faktör yapısının doğrulanması için elde edilen verilere DFA uygulanmıştır. DFA sonucunda incelenen 9 uyum iyiliği indeksinin çoğunluğunda $(\chi 2 / \mathrm{sd}=1.72$, $\mathrm{CFI}=.96, \mathrm{NNFI}=.96, \mathrm{IFI}=.96, \mathrm{RMSEA}=.05, \mathrm{SRMR}=.05$ ) mükemmel uyum tespit edilmiştir. $\mathrm{Bu}$ şekilde öngörülen faktör yapısının yeni veri üzerinden gerçekleştirilen DFA ile doğrulandığı tespit edilmiştir. Ölçeğin dış ölçüt geçerliğine yönelik olarak RSKÖ ile toplam ve alt boyut puanları ile DuSKÖ toplam ve alt boyut puanları arasındaki korelasyonu incelenmiştir. Ölçeğin güvenirliği Cronbach Alfa $\left(\alpha_{\text {Bilişsel }}=.93, \alpha_{\text {Psikososyal }}=.84, \alpha_{\text {Fizyolojik }}=.85 \alpha_{\text {DuSKÖ= }} .94\right)$, Spearman-Brown iki yarılar güvenirliği ve testtekrar test teknikleri ile incelenmiştir. Tüm bu tekniklerden elde edilen katsayılar ölçeğin güvenilirliği konusundan olumlu sonuçlar elde edildiğinin göstergesi olarak alınmıştır.

DuSKÖ'nün alt boyutları arasındaki korelasyon değerleri incelendiğinde Psikososyal boyutun diğer alt boyutlarla korelasyonu fizyolojik ve bilişsel alt boyutlar için sırasıyla .49 ve .65 olmuştur. Ölçek toplamı ile korelasyonu ise .73 gibi yüksek bir değer almıştır. Bu bulgular psikososyal boyutun diğer alt boyutlardan farklı bir boyut olduğunu kanıtlar niteliktedir. Bu durum alanyazında tartışıldığı üzere önce tek boyutlu ölçeklerle başlayan sınav kaygısı ölçeği geliştirme çalışmalarının 1970 başlarında şu an mevcut ölçeklerin çoğuna yansıdığı şekliyle iki boyutlu yapısının son yıllardaki çalışmalarda da görüldüğü ve yavaş yavaş kabul gördüğü üzere en azından Türkiye bağlamında üç boyutlu olduğunun göstergesidir. Bu bulgu DuSKÖ'nün bu açıdan yerli alanyazına önemli katkılar sağlama potansiyeline sahip bir ölçek olarak değerlendirilmesine yolaçacağını düşündürmektedir.

Elde edilen veriler 1şı ğında bu çalışmada geliştirilen DusKÖ’nün üniversite düzeyinde bireyler için sınav öncesi kaygı düzeylerinin belirlenmesinde kullanılabilecek geçerli ve güvenilir bir ölçek olduğu söylenebilir. Bu ölçeğin alanyazına kazandırılması sonucu sürekli kaygı ile durumluk kaygı arasındaki ilişki düzeyinin tespit edilmesinde, düşük veya yüksek sürekli kaygıya sahip bireylerin kaygı düzeylerinde beklenmeyen artışa ya da düşüş̧e neden olan derslerin ya da özel durumların belirlenmesinde kullanılması öngörülmektedir. Ayrıca DuSKÖ'nün yapısı gereği hemen sınav öncesi uygulanması nedeniyle sürekli sınav kaygısına yönelik hazırlanmış ve sınav ortamından ziyade sınıf ortamında yanıtlanan ölçeklere göre daha geçerli ve güvenilir sonuçlar vermesi beklenmektedir. İki grup ölçeğin kaygının sınav notlarına yansıması açısından karşılaştırılması şeklinde bir çalışmada performanslarının karşılaştırılabileceği öngörülmektedir. 


\section{KAYNAKLAR}

Akın, A., Demirci, İ., \& Arslan, S. (2012). Revize edilmiş sınav kaygısı ölçeği: Geçerlik ve güvenirlik çalışması. Eğitim Bilimleri ve Uygulama, 11(21), 103-118.

Başol, G. (2017). Ayda sınav kaygısı ölçeği : Geçerlik ve güvenirlik çalışması. Uluslararası Eğitim Bilimleri Dergisi, 4(13), 173-193.

Benson, J., \& El-Zahhar, N. (1994). Further refinement and validation of the revised test anxiety scale. Structural Equation Modelling, 1, 203-221.

Bozkurt, S., Ekitli, G. B., Thomas, C. L., \& Cassady, J. C. (2017). Validation of the Turkish version of the cognitive test anxiety scale-Revised. Sage Open, 1, 1-9. doi: 10.1177/2158244016669549

Çokluk, Ö., Şekercioğlu, G., \& Büyüköztürk, Ş. (2010). Çok değişkenli istatistik SPSS ve LISREL uygulamaları (Birinci baskı). Ankara: Pegem Akademi Yayınları.

Delvecchio, E., Cavallina, C., Di Riso, D., \& Mazzeschi, C. (2017). Early evidence of Italian validation of the trait anxiety scale of the state trait anxiety inventory for children. European Journal of Developmental Psychology, 15(2), 214-223. doi:10.1080/17405629.2017.1297227

Driscoll, R. (2007). Westside test anxiety scale validation. Marion, IN: Indiana Wesleyan Center for Educational Excellence.

Erkuş, A. (2012). Psikolojide ölçme ve ölçek geliştirme-I: Temel kavramlar. Ankara: Pegem Akademi Yayınları

Eum, K., \& Rice, K. G. (2011). Test anxiety, perfectionism, goal orientation, and academic performance. Anxiety, Stress \& Coping, 24, 167-178. doi : 10.1080/10615806.2010.488723

Friedman, I. A., \& Bendas-Jacob, O. (1997). Measuring perceived test anxiety in adolescents: A self-report scale. Educational and Psychological Measurement, 57, 1035-1046. doi:10.1177/0013164497057006012

Gençdoğan, B. (2006). Lise öğrencilerinin sınav kaygısı ile boyun eğicilik düzeyleri ve sosyal destek algısı arasındaki ilişkiler. Atatürk Üniversitesi Sosyal Bilimler Enstitüsü Dergisi, 7, 153-164.

Gündoğdu, M. (1994). The relationship between helpless explanatory style, test anxiety and academic achievement among sixth grade basic education students (Yayınlanmamış Yüksek Lisans Tezi). ODTÜ, Ankara.

IBM Corp. (2016). IBM SPSS Statistics for Windows, Version 24.0. Armonk, NY: IBM Corp.

Jöreskog, K. G., \& Sörbom, D. (2001). LISREL 8.5 for Windows [Computer software]. Lincolnwood, IL: Scientific Software International, Inc.

Kahraman, S., Özbaşı, D., \& Özdemir, M. (2018). Powerpoint'in derste kullanılmasına ilişkin tutum ölçeği geliştirme çalışması. Kastamonu Education Journal, 26(4), 1237-1246. doi:10.24106/kefdergi.434168

Karataş, H., Alıc1, B., \& Aydın, H. (2013). Correlation among high school senior students' test anxiety, academic performance and points of university entrance exam. Educational Research and Reviews, 8, 919-926. doi: 10.5897/ERR2013.1462

Liebert, R. M., \& Morris, L.W. (1967). Cognitive and emotional components of test anxiety: A distinction and some initial data. Psychological Reports, 20, 975-978.

Lowe, P. A., Lee, S. W., Witteborg, K. M., Prichard, K. W., Luhr, M. E., Cullinan, C. M., . ., \& Janik, M. (2007). The test anxiety inventory for children and adolescents (TAICA): Examination of the psychometric properties of a new multidimensional measure of test anxiety among elementary and secondary school students. Journal of Psychoeducational Assessment, 26, 215-230. doi:10.1177/0734282907303760

Öner, N., \& LeCompte, A. (1998). Sınav kaygısı envanteri el kitabı. İstanbul : Yüksek Öğrenimde Rehberliği Tanıtma ve Rehber Yetiştirme Vakfi Yayınları.

McDonald, A. S. (2001). The prevalence and effects of test anxiety in school children. Educational Psychology, 83, 134-139. doi: 10.1080/01443410020019867

Schermelleh-Engel, K., \& Moosbrugger, H. (2003). Structural equation models: Tests of significance and descriptive goodness-of-fit measures. Methods of Psychological Research Online, 8 (2), 23-74.

Spielberger, C. D. (1972). Theory and research in anxiety. New York: Academic Press.

Spielberger, C. D. (1980). Test anxiety inventory: Preliminary professional manual. Palo Alto, CA:Consulting Psychologists Press.

Spielberger, C. D., Gorsuch, R. L. \& Lushene, R. E. (1970). Manual for state-trait anxiety inventory. Palo Alto, CA:Consulting Psychologists Press.

Spielberger, C. D., \& Vagg, P. R. (1995). Test anxiety: A transactional process model. In C. D. Spielberger \& P. R. Vagg (Eds.), Test anxiety : Theory, assessment, and treatment (pp. 3-14). Washington, DC: Taylor \& Francis.

Tabachnick, B. G., \& Fidell, L. S. (2012). Using multivariate statistics. Boston, MA: Allyn \& Bacon/Pearson Education.

Totan, T. \& Yavuz, Y. (2009). Westside sınav kaygısı ölçeğinin Türkçe formunun geçerlik ve güvenirlik çalışması. Mehmet Akif Ersoy Üniversitesi Ĕ̈itim Fakültesi Dergisi, 17, 95-109.

Zeidner, M. (1998). Test anxiety: The state of the art. New York : Plenum. 


\section{Durumluk Sınav Kaygısı Ölçeği (DuSKÖ)}

1- Hiç 2-Biraz 3- Orta Düzeyde 4-Çok

\begin{tabular}{|c|c|c|c|c|c|c|}
\hline $\mathrm{D}^{*}$ & $\mathrm{~N}^{*}$ & & 1 & 2 & 3 & 4 \\
\hline 1 & 1. & Nefes almakta güçlük çekiyorum. & & & & \\
\hline 7 & 2. & Midem bulanıyor. & & & & \\
\hline 6 & 3. & Kendimi gergin hissediyorum. & & & & \\
\hline 15 & 4. & Sınavı yetiştiremeyeceğimden korkuyorum. & & & & \\
\hline 10 & 5. & A ğzım kuruyor. & & & & \\
\hline 24 & 6. & Sınav kağıdımı benden başkasının görmesinden çekiniyorum & & & & \\
\hline 19 & 7. & Sınavda cevapları bulamayacağımdan korkuyorum. & & & & \\
\hline 14 & 8. & Karnım ağrıyor. & & & & \\
\hline 22 & 9. & Sinavda okuduğumu anlamamaktan çekiniyorum. & & & & \\
\hline 27 & 10. & $\begin{array}{l}\text { Sınavdan düşük not alırsam arkadaşlarıma alay konusu olmaktan } \\
\text { çekiniyorum }\end{array}$ & & & & \\
\hline 16 & 11. & Kaslarım normalden daha gergin. & & & & \\
\hline 28 & 12. & $\begin{array}{l}\text { Sinavdan düşük not alırsam ailemden tepki göreceğimi } \\
\text { düşünüyorum. }\end{array}$ & & & & \\
\hline 29 & 13. & $\begin{array}{l}\text { Sınavdan düşük not alırsam öğretmenimin gözünde küçük } \\
\text { düşeceğimi düşünüyorum. }\end{array}$ & & & & \\
\hline 21 & 14. & Sınavda cevapları hatırlamakta güçlük çekeceğimden çekiniyorum. & & & & \\
\hline 17 & 15. & Ateşim yükseldi. & & & & \\
\hline 18 & 16. & Sınavda başarısız olmaktan korkuyorum. & & & & \\
\hline 2 & 17. & Başım ağriyor. & & & & \\
\hline 25 & 18. & Sınavdan düşük not alırsam üzüleceğim. & & & & \\
\hline 8 & 19. & Mideme kramp giriyor. & & & & \\
\hline 26 & 20. & $\begin{array}{l}\text { Gerginliğimin sınav notumun düşmesine sebep olmasından } \\
\text { çekiniyorum. }\end{array}$ & & & & \\
\hline 23 & 21. & Sınav notumu başkalarının duyacağından çekiniyorum. & & & & \\
\hline 20 & 22. & Keşke sınava daha fazla çalışsaydım diye düşünüyorum. & & & & \\
\hline
\end{tabular}

*D=Deneme, $\mathrm{N}=$ Nihai uygulamalardaki madde numarasını ifade etmektedir. 